\title{
THE
}

$4-27-2011$

\section{New England Technical Services Librarians Spring 2011 Conference: 2020 Vision: A New Decade for Technical Services}

Andree J. Rathemacher

University of Rhode Island Library, andree@uri.edu

Michael A. Cerbo II

University of Rhode Island, mcerbo@uri.edu

Yuan Li

Syracuse University, yli115@syr.edu

Follow this and additional works at: https://digitalcommons.uri.edu/lib_ts_pubs

Part of the Library and Information Science Commons

\section{Citation/Publisher Attribution}

Rathemacher, Andree J., Michael A. Cerbo, and Yuan Li. "New England Technical Services Librarians Spring 2011 Conference: 2020 Vision: A New Decade for Technical Services." , (2011). doi: 10.1016/ j.serrev.2011.05.011.

This Article is brought to you for free and open access by the Technical Services at DigitalCommons@URI. It has been accepted for inclusion in Technical Services Department Faculty Publications by an authorized administrator of DigitalCommons@URI. For more information, please contact digitalcommons-group@uri.edu. 
New England Technical Services Librarians Spring 2011 Conference: 2020 Vision: A New Decade for Technical Services

Andrée J. Rathemacher, Michael A. Cerbo II, and Yuan Li

This report discusses the program of the 2011 New England Technical Services Librarians (NETSL) annual spring conference, held on Friday, April 8 at the College of the Holy Cross in Worcester, Massachusetts and entitled "2020 Vision: A New Decade for Technical Services." NETSL is a section of the New England Library Association and a regional group of the American Library Association.

\section{Innovate or Become Obsolete: Technical Services Staffing for the $21^{\text {st }}$ Century}

The morning keynote speaker, Bradford Lee Eden (associate university librarian for Technical Services \& Scholarly Communication, University of California, Santa Barbara) spoke on technical services staffing for the twenty-first century. Eden stated that he was speaking from the position of library administrator, a position that "broadens perspective and focus, but may not be welcomed."

Eden reviewed a list of catalysts for change in libraries. He noted that state support for higher education will continue to decline, as higher education is no longer perceived as a public good. The Google book settlement will eventually be approved in some form, at which time Google Books will replace print collections and Google will become "another Elsevier." Social 
networking is prevalent; we work in an environment in which we can talk to anyone in the world at any time. Print collections are moving off-site through distributed print repositories like the Western Regional Storage Trust as the full costs of open stack storage are recognized and the need to accommodate people and collections puts demands on library space. In some cases, technical services staff are being relocated outside libraries. Meanwhile, libraries are shifting resources to provide access to unique local collections.

At the same time, libraries are moving from the local level to the network level in terms of collaboration, metadata, and resource sharing, of which the University of California's implementation of WorldCat Local is an example. Local and regional consortiums are not enough, and they are no longer affordable; we need mega consortiums. As technical services work flows are streamlined through efforts such as the University of California's NextGeneration Technical Services initiative, technical services staff can be involved in open access and scholarly communication initiatives. Institutional repositories are the future. It will be the job of libraries to assist faculty in preserving digital data as mandated by the National Institutes of Health and the National Science Foundation and to educate faculty about copyright issues and the importance of retaining their rights as authors.

Another catalyst for change is new technologies and the shift toward mobile devices. Students need media literacy, not information literacy. As librarians, we need to understand what can be done with media devices and educate students in their use, for example in exploring 3D information visualization resources currently available. This is how users want to learn, not by 
opening a book. At the same time, we are faced with the need for assessment. In this climate of budget cutting, we are expected to continually prove our value to our parent institutions. Higher education administrators used to think of libraries and information technology as black holes into which they threw money; now they have simply stopped throwing the money. Appeals for increased book budgets no longer hold sway at the provost level; administrators want immediate results and "bang for the buck." Finally, the library catalog is in a state of flux, with competition to proprietary integrated library system vendors through open source solutions such as Pines/Evergreen and Koha and from OCLC's Web Scale Management Services.

In the context of these changes, Eden asserted that library directors face three big issues. The first is the costs involved in maintaining, updating, and researching bibliographic records. This includes costs from bibliographic utilities like OCLC and library system vendors, personnel costs, and redundant work in support of local practices that are no longer sustainable. The second issue is that users no longer think of the library and the online catalog as the first option for obtaining information; the library is usually the last option, if an option at all. And third, if and when the current economic crisis goes away, staffing in libraries will never go back to previous levels.

In light of these issues, Eden believes that technical services librarians need to end the status quo and be comfortable with the concept of "good enough." Eden pointed out that the Library of Congress has moved staff and resources from cataloging to the digitization of unique resources and that Google is the number one way that people begin their information searches. The 
precision and exactness of bibliographic records, while laudable and of value in the long term, is neither sustainable nor marketable in the current information environment. Libraries walked away twenty-five years ago when faculty asked for help creating metadata standards for their disciplines, but now this is what we need to be doing. Librarians need to assist faculty in creating crosswalks between various metadata standards.

Eden suggested that technical services librarians learn to be proactive rather than reactive. They should "lean into their discomfort" and learn new skills. They also need perspective and should "work to live, not the other way around." Eden told the audience that, "If you live to work, you have a problem. It's just a job. When you go home, do you really need to worry about the Library of Congress?" Library administrators, in these tough budget times, are looking for staff members who maintain a positive attitude toward change and life, who are willing to grow and learn both professionally and personally, and who can work outside of their comfort zone when it comes to helping the library to fulfill its mission and goals. On a concrete level, Eden suggested that technical services librarians ask for professional development opportunities through Webinars (given that little money exists to support conference attendance). They should assist, not hinder, reorganization efforts and be willing to volunteer in patron-facing areas of the library that might need assistance due to staff shortages, for example circulation or interlibrary loan. Technical services librarians should learn non-MARC metadata so they can apply their expertise in the organization and description of print resources to the digital environment. They should also learn scanning and digitization skills so that metadata can be assigned to digital objects at the time of creation. 
At the departmental level, Eden offered several points of advice. He suggested conducting a process review of all current workflows, revising and redesigning them for efficiency. Backlogs should be eliminated, even if that means cataloging some resources with brief records, since any access is better than none. Acquisitions departments should contract with book vendors to provide all English-language print materials in shelf-ready format. After establishing an acceptable rate of error, incoming print materials should be reviewed only once or twice a year. Technical services librarians should be provided with the training needed to digitize unique collections and describe them using non-MARC metadata standards. They should also be trained to offer metadata support and research planning assistance for faculty and students working with data sets. Project management skills will be in high demand.

Eden summarized a symposium report by Susan Gibbons, “Time Horizon 2020: Library Renaissance" (http://www.ala.org/ala/mgrps/divs/alcts/resources/z687/gibbons.pdf) in which she stated that "technical services and collection development will be at the center of the next significant phase of library transformation." Gibbons sees the distinction between interlibrary loan and acquisitions dissolving as collections are delivered just-in-time in response to user needs. Resources will shift "towards the identification, preservation, and some level of republication of books held uniquely by each library," and the emphasis of technical services will change from the acquisition of content to the user's discovery of content, especially locally created materials. 
In conclusion, Eden stated that success for technical services librarians in the coming years will come from maintaining a sense of perspective. Throughout his career, he has found that success has been based primarily on mindset and attitude, and only minimally on knowing specific processes and techniques. He suggested that attendees get rid of limiting habits and beliefs that slow them down and that they find the confidence to dream and act big. Eden rhetorically asked audience members what their position was on the future of their careers and then presented two options in response. The reactive option involves whining, complaining, being uncooperative and angry, and holding back progress. The proactive option involves being accepting, moving forward, assisting, experimenting, and learning.

\section{The "Unified Discovery Platform” and the Library Catalog: Teammates or Rivals?}

Following the morning keynote address, four concurrent breakout sessions were offered. In one, Cecilia P. Tittemore (head of Cataloging and Metadata Services, Dartmouth College Library) presented a comparison of Serials Solutions' Summon discovery platform to the traditional library catalog.

Summon is a discovery platform developed by Serials Solutions that allows patrons to search the entire library catalog along with other information resources that are available through the Web. Through Summon, the 2.5 million resources in the Dartmouth College library catalog are expended to 274 million. Summon can be described as a single portal that allows users access to the catalog and databases, plus much more. 
Tittemore characterized the difference in metadata standards between the library catalog and the discovery platform as the difference between a highly structured versus a blended metadata structure. Whereas library catalogs retrieve items using searchable vocabulary based on established standards (e.g. Anglo-American Cataloging Rules and Resource Description and Access) and do not rank search results by relevance, discovery platforms use a more Internetbased approach. In this method, many different sources and formats of metadata are searched, even full text, and relevancy ranking of results is essential. Discovery platforms use a single search box as an easy entry point, familiar to many users in this "Google age."

Dartmouth College was a beta-tester for Summon, helping to "tweak" the tool to better meet the needs of their users. After extensive user testing, there emerged a clear undergraduate preference for the unified discovery platform. On the other hand, most graduate students and researchers preferred the traditional library catalog to the broader but less accurate Summon. Since the library catalog works with controlled vocabularies, there is a limit to what is retrieved by a search, and users must refine their search terms to improve their search results. A discovery platform accepts any term and uses a relevancy ranking to try to determine what the user is looking for. This is acceptable if the terms searched for and the items needed are a match. When they are not, the user is left with many irrelevant results to sort through. When a sample search was performed in both systems, the Dartmouth Catalog returned under 300 results, while the same search using Dartmouth's Summon gave 43,000+ results. 
Tittemore did not favor one system over another. The point of her presentation was to show how each system approached research in a different way. A search in the library catalog is more focused and produces more precise results, while Summon delivers all related information to the user in a "relevancy ranking." As a discovery platform produces a much greater number or results, the ability to establish what is actually available or relevant falls to the user.

\section{Research Data and Libraries}

In another morning breakout session, Donna Kafel (project coordinator, Lamar Soutter Library, University of Massachusetts (UMass) Medical School) and Rebecca Reznik-Zellen (science librarian, Center for Hierarchical Manufacturing, University of Massachusetts Amherst) discussed the new role of libraries in curating or assisting faculty in managing research data throughout the research life cycle. The need for research data management has grown as funding agencies have instituted requirements for investigators to provide plans for coordinated and distributed sharing and archiving of research data.

Kafel began by reviewing the definition of research data, the various types and formats of data generated by different research areas, and possible components of the data. She explained related concepts, such as E-Science, cyber infrastructure, data management, and data curation and identified stages in the research process, or the research data life cycle, when researchers might benefit from interacting with librarians. 
Reznik-Zellen explained the importance of managing research data and why libraries are taking a leading role in doing so. Proper management of research data protects federal investments in research and development by ensuring the data's continued availability. The sharing of data expedites the scientific process and increases research efficiency by preventing duplication of effort and enabling the reuse of data. Moreover, plans to manage research data are now required by many funding agencies, and the archiving of research data has been a common practice in industry and commerce. Libraries have begun to consider the collection and management of research data as falling within their scope of responsibility. Furthermore, units on campus other than the library have neither the expertise nor the infrastructure to manage research data.

During the second half of the breakout session, Kafel and Reznik-Zellen shared the UMass System libraries' response to research data and current practices on the UMass Medical and UMass Amherst campuses. In 2008, five science librarians in the UMass System formed an Ad Hoc Committee for E-Science. The activities of the committee included exploring shared electronic resources, drafting principles fundamental to E-Science, and creating professional development and continuing education opportunities. The committee has also organized a series of annual events, now in their third year, including Professional Development Day, an E-Science Symposium, and a Science Boot Camp. At UMass Amherst, the library established a Data Working Group to determine if the university libraries should accept broad responsibility for curating research data and, if so, how that should be done, what would be expected, and who would be involved. In 2009, the library at UMass Medical conducted a learning needs assessment of New England science and medical libraries for planning continuing education programs, developed the e-Science Portal for New England Librarians 
(http://esciencelibrary.umassmed.edu) and conducted a survey regarding data management competencies among New England science and medical librarians. In 2010, the Lamar Soutter Library at the University of Massachusetts Medical School and the George C. Gordon Library at Worcester Polytechnic Institute were awarded an Institute of Museum and Library Services National Leadership Collaborative Planning Grant. With this grant, the two libraries are collaboratively developing an instructional framework and delivery system for openly accessible, online instruction modules on preserving, managing, and sharing digital data. The primary goal of the project is to teach essential data management skills early in the training programs of both science and medical professionals.

The presenters mentioned other institutional and large-scale consortial approaches to research data management. There are essentially three levels of approach: informational or educational, consultative, and technical. The informational or educational approach involves creating a Web page to provide information and links to resources. The consultative approach involves providing consultation regarding data management plans and helping researchers decide how and where to store their data. The technical approach involves providing the technical infrastructure to track and support research data and data management plans. At this point, UMass Amherst and UMass Medical School are operating on the informational and educational level only.

Kafel and Reznik-Zellen concluded the session by sharing the current practices of New England libraries regarding research data and the findings from their data management skills/competencies survey. The current practices of New England libraries with regard to 
research data are: initiating projects to understand the scope of campus data management needs, i.e. education and environmental scanning; working with departments on campus to determine best practices for data management; developing formal policies for data management support; reorganizing libraries to create departments for specialized content; conducting data interviews with researchers; evaluating requirements for institutional data repositories; and consulting with researchers on data management plans. Data management skills/competencies for librarians working with research data include understanding research methods, data lifecycle, and data security; building, populating and maintaining digital databases; using a variety of programming languages (e.g. XML, SQL); knowledge of metadata standards (interoperability standards, Dublin Core, MODS, OAI_PMH, etc.); working with metadata manipulation, crosswalks, validation, and portals; providing data mining, interpretation, representation, and visualization services; working with and developing digital lab notebook applications; promoting digital data sharing, open access, and/or participation in institutional repositories; and developing the ability to work collaboratively with library, information technology, institutional review board, and faculty colleagues.

\section{The User Knows Best: Patron Driven Acquisitions and the Death of "Expertise"}

In a third morning breakout session, Peter Spitzform and Deborah Lenares presented their experiences with patron-driven acquisition of print and electronic books. Spitzform (collection development librarian, Bailey/Howe Library, University of Vermont (UVM)) described how UVM worked with YBP Library Services (YBP) to create a pilot project that allows patrons to select print books. Part of the library's $\$ 800,000$ book budget is set aside for this purpose. 
The library wished to test the hypothesis that books selected by patrons at the point of need would be used more frequently than books selected by librarians using a just-in-case model of collection development. YBP worked with the library to load MARC records into their Voyager catalog for books they did not own, based on their approval plan, from three major publishers, Wiley, Palgrave Macmillan, and Oxford University Press.

When a patron encounters a catalog record for one of these books, the location of the book appears as "Order On Demand," and a button in the full record invites the patron to "Request This Book." The patron is notified that this is a free service and is prompted to enter her name, phone number, e-mail address, UVM status and an indication of how urgently she needs the book ("as soon as possible," "in a week or so," "not in a hurry," or "do not want to be notified when book arrives"). Books that the patron needs quickly are rush-ordered from YBP, amazon.com, or barnesandnoble.com with the goal of getting the book into the patron's hands three working days from the placement of the order.

The program went live in November 2007, and as of March 31, 2011, 1,536 books have been ordered. In the last fiscal year, 590 books were ordered, whereas the number of books matching the same criteria that the library would have received through their approval plan during this time would have been 1,502. Thus, the library avoided purchasing 912 books, saving over $\$ 50,000$ and about ninety linear feet of shelf space. Since the inception of the program, orderon-demand books have circulated an average of two times, while books received over the same 
time period the traditional way have circulated an average of 1.18 times. Spitzform explained that the MARC records for the books that were not purchased will remain in the catalog for the long term. Since books are not going out of print as quickly as they used to, and since publishers have begun to print books on demand, Spitzform expects that any books not purchased but needed in the future will be available.

Spitzform added that UVM has begun a new pilot program in which they are working with YBP and EBL (Ebook Library) to integrate patron-driven acquisition of e-books in the library's approval profile with YBP. When available, records for e-books from the same three publishers have been loaded in the UVM catalog. Records are de-duplicated so that only one record, for the e-book or the print, remains in the catalog. Patron access to the e-book triggers a short-term loan or a purchase after the third use. YBP continues to handle billing for books in both formats.

Spitzform concluded that, in an environment of limited financial resources, UVM has continued to offer access to the same amount of materials as in the past. It is no longer the case that libraries can afford to be great repositories of knowledge with "all of the books lined up like good soldiers on the shelves." That worked during the post World War II period up until about ten years ago, but it doesn't work anymore. What is important now is discoverability and getting needed items to patrons in a timely way. 
Speaking next was Deborah Lenares (manager of acquisitions and resource sharing, Wellesley College). Lenares presented a list of concerns commonly expressed about patron-driven acquisitions and discussed each one in turn. The first common concern is that collections will become non-scholarly and unbalanced. Lenares believes this fear is unfounded, as librarians have control over what records they load into the catalog. She added that when she has reviewed alerts that were sent to her whenever a title was purchased for Wellesley, she was impressed by the appropriateness for the collection of the titles selected. A second concern with patron-driven acquisitions is a perceived inability to control costs. Lenares countered that this is not a problem if librarians have a plan about how much money to allocate to the PDA program, how often funds will be replenished, and how to withdraw from the program if expenditures cannot be sustained. A third concern with PDA is that not enough scholarly titles are available as e-books through vendor PDA programs. Lenares feels that this concern, too, is overstated. The biggest problem, she has found, is that many scholarly e-books are not available until a period after the print version of the book is released. For this reason, Lenares advises that libraries should not yet replace their print approval plans with PDA initiatives. One concern that Lenares believes is a problem is digital rights management restrictions and limitations on interlibrary loan. In a consortial environment, libraries are used to sharing materials, and limitations on interlibrary loans of e-books make sharing of these materials impossible. Fortunately, different groups are actively working with vendors to create solutions to this issue. Another problem is restrictions on copying and printing. Most library users accept that licensed content cannot be freely shared, but patrons want to copy and paste and print e-book sections that they need. Another concern about PDA is the the staff time needed to monitor and maintain these programs. Lenares conceded that significant staff time is required to offer this new service; however, the time 
required is far less than the time spent by book selectors and ordering and processing staff on title-by-title orders. A final concern about patron-driven e-book programs is the fact that some patrons don't like e-books. This may be true, Lenares responded, but many people do like ebooks. In fact, she often asks faculty requesting a book if they would be interested in waiting for the library to purchase the e-book version, and many agree because the e-book will be accessible remotely to more than one reader at a time.

Lenares highlighted some important lessons learned through Wellesley's experience with purchasing e-books. One is that is that copying and printing are very important to patrons. Ebook interfaces need to clearly indicate how much copying and printing is allowed and how these functions are accomplished. Multiple simultaneous users are also essential. When books are available online, patrons cannot understand the concept of "checked out." Integrating the ebook PDA program with the library's regular book vendor is also critical. This allows selectors to see which books are available through PDA, therefore avoiding unnecessary ordering of print copies. The "free browse" period available through EBL is also useful. Patrons are allowed to view any titles for five minutes at no charge, after which they are asked if they want to check out the book. EBL's short term loans cost 10-15 percent of the list price of the book. Only on the third loan is a purchase triggered. The combination of free browse and short-term loans lowers costs significantly, according to Lenares. She determined that over eighteen months, about half of all browsed titles were checked out as short-term loans, and only 5 percent of browsed titles ended up being purchased. Compared to print books published during the same time period, 2007-2009, purchased PDA e-book titles circulated 3.00 times, while the average print title circulated only 0.79 times. Furthermore, since each PDA title had been "borrowed" twice before 
it was purchased, the difference between use of PDA and print titles was even more marked, especially considering that all e-book use took place over eighteen months, while print titles published during the same time period had been available from two to six years.

Lenares concluded by discussing the costs of the PDA program. While e-book expenditures rise and fall over the course of the year, peaking sharply at busy times of the semester and right before the semester begins, the overall trend line of dollars spent rises only gradually. She advised those interested in pursuing a similar program to select a vendor wisely and start with a small amount of money over a broad set of subject areas — in order to get buy-in from all selectors - and to craft a profile with care. Libraries pursuing PDA of e-books should evaluate their program continually and devise a plan to increase funding if the project is successful and to withdraw records from the catalog if it proves financially unsustainable.

\section{View from the Top: Future Organization and Innovation in Technical Services}

Following lunch, Amy Hart (Minuteman Library Network) moderated a panel of two library directors on how libraries will change in the next ten years and how technical services functions will adapt to those changes. Speaking first was Jay Schafer (director of libraries, University of Massachusetts, Amherst). Shafer contended that libraries are facing a perfect storm with the digital revolution and the global economic downturn, and that the biggest challenge for libraries is not inadequate budgets, but adapting to the digital environment. 
Shafer highlighted some of the changes that are already affecting libraries and technical services as resources have shifted from print to digital format. Our tasks and tools have been transformed, and changes in methods of discovery are impacting everything we do. He believes that the cloud catalog will be the next big leap in technical services. There is no reason for individual libraries to have their own isolated catalogs, which are too costly and labor-intensive to maintain. Selection of monographs has also become easier; with vendors' online systems, books can be selected and ordered at the same time.

Shafer discussed how the University of Massachusetts at Amherst had already moved ahead with many of these changes during the last recession, in 2003. At that time, they consolidated book vendors, moved to online selection of books, and began to receive their books shelf-ready. Collection decisions were based on use and expedited document delivery services were instituted, as the library pursued a "just in time" rather than a "just in case" philosophy of collection building.

During the current recession, the Five Colleges Consortium (Amherst College, Hampshire College, Mount Holyoke College, Smith College and the University of Massachusetts, Amherst) have increased their level of collaboration. The consortium has adopted the goals of unifying the user experience across the five libraries, maximizing efficiencies so staff can deal with new "twenty-first century" tasks, and providing cost savings where possible. The libraries had hoped to consolidate technical services for print materials into one, centralized department, but organizational and human resource issues made this impossible. Nonetheless, the libraries now 
share a common book vendor, order books shelf-ready, and have reduced unnecessary duplication between their collections.

A present goal of the Five Colleges is to acquire as many common collections of e-resources as possible with the goal of making the user experience the same across the five campuses. The institutions are working to implement a common discovery tool to supplement the online catalog and A-to-Z journal and database lists. Another shared goal is expedited article delivery between the campuses.

Shafer explained that these collaborations have not been uniformly well-received by staff, some of whom perceive that their past work is being disrespected. Cataloging and reference staff believe that their work adds local value for users at their own institutions, value which will be lost with a loss of local control.

Shafer ended by presenting a vision of the library in five to ten years. Collections, discovery, and technical services will all exist in the cloud, and the emphasis of libraries will shift to special collections and the preservation of local, digital scholarship. Print collections will be small, print-on-demand services will be offered, and legacy print collections will be relocated to depositories. Significant activities of technical services staff will include licensing content, working with multi-media, digitization, e-publishing, and data curation of locally created 
resources through institutional repositories and other tools. In the face of these changes, we need to remain adaptable to survive.

Kendall Wiggin (Connecticut State Librarian), spoke next. He stressed the importance of designing for the user as we design new systems in libraries. Usability testing is critical, and technical services librarians should know how to conduct usability studies. For example, online catalogs were designed for librarians, not users. Library users expect to access libraries using a variety of media and to find what they are looking for in one or two clicks. Most users do not want a multitude of search tools or advanced searching capabilities; they like a single search box. Vendors are offering libraries new discovery technologies that replace advanced searching with facets that appear in sidebars, which users find more intuitive. Vendor databases also have autofill to suggest search terms to patrons, an improvement over the library catalog which presents Library of Congress Subject Headings that users don't understand. One library that has paid attention to the user perspective is Darien Public Library. They have organized their library more like a bookstore, with books organized into broad categories like "self-help" or "yoga," even if the books are not in call number order on the shelves.

Libraries can be more user-centered by creating more pathfinders. This sounds old-fashioned, but we still need to guide patrons through our collections, especially because the catalog is not easy to use. We can put pathfinders on the Web and help drive people to our collections. We can use popular, Web-based tools such as Facebook, Twitter, and Flickr to reach out to users and bring them into the library. When we post an image to Flickr, the quality of the online image is 
not as important as letting people know that we have the image in our collections. We can also forge closer ties with our communities by adding links from our discovery tools to local online resources, for example to an online poetry collection written by one of the library's users. We will need to add items to our collections that we had reason not to in the past, but with digital resources, old restrictions need not apply.

Wiggin again emphasized that library users' ability to find information easily should be our primary concern. Our digital collections should be brought together into one place for ease of discovery. Instead of replacing or rebinding worn-out print books, we should link to digital copies online when available. We should learn to accept "good enough" digitization and metadata standards, as long as people can find an object. Early digital projects went awry because they tried to over-describe the items in the collection. It would be better to allow users to add data themselves through user-generated tags. We need to be open to the community adding metadata and therefore value to our online collections.

Wiggin believes that technical services is not obsolete, but a great deal of what we do is outmoded. One of the biggest change factors in libraries will be retirements and the opportunity they present for changing how things are done. Library directors need to define the new skill sets they will need and have new position descriptions ready before retirements take place. Silos in libraries need to be broken down, and collaboration needs to increase within and between institutions in order to minimize duplication of effort. 
Changes in the information landscape are bringing other changes that will require adjustment. We need to be honest about what printed materials we need to preserve, especially if items exist in other libraries' collections. We need to accept the fact that we are moving from copyright to licensing in terms of e-books. We need to reevaluate the statistics we gather, continuing to collect some and stopping gathering those which we no longer know why we collect. Librarians need to develop the skills sets to interpret statistics.

Wiggin concluded that technical services will remain in some form, but we cannot continue to perform technical services work as we have done in the past. We need to relax metadata standards when appropriate in order to make material, especially online material, available sooner, with the knowledge that additional metadata can be added later. In the end, directors do not want to do away with technical services; they want to work with technical services staff to make library services more effective for the library user.

\section{A Future for Libraries}

The afternoon keynote address was given by John Palfrey (vice dean for library and information resources, Harvard Law School). In his address, Palfrey painted an optimistic picture of the future of libraries in a changing information landscape. Three years ago, when he was appointed director of the Harvard Law School Library, friends joked that his job would be to get rid of the library in the age of Google. It was then that Palfrey realized that he needed an argument for the future of libraries. 
According to Palfrey, the young people of today do not picture a library filled with books when they think about accessing information. They were born digital and are connected to the network at all times. Libraries need to define themselves as hybrid spaces, between the print and digital worlds, in order to meet young people where they are. Palfrey wants the library to be the place "where the cool kids hang out," and Harvard Law School Library is that place. Even though patrons are not pulling as many books off the shelves, the library is packed, and during exams space is so limited that they need to reserve the library for law school students only.

Palfrey explained that young people are not distracted; they are multitasking. They are able to do more than one thing at once, for example doing their homework while looking at Facebook. They are receiving news and information all the time, increasingly through mobile devices in interstitial moments during the day. The monopoly of libraries and teachers in the classroom as the primary sources of credible information is long gone. Our problem is that, while media is increasingly consumed in digital format, libraries spend most of their time dealing with print and textual sources in traditional ways. We are not as good at dealing with other types of media. Young people prefer the digital format over a tangible format in almost every category: digital audio files, photographs, videos, news stories, journal articles. The one strange anomaly to this digital preference is books. One survey of Harvard Law School students showed that 75 percent preferred print format for books. For long form arguments, we still want a printed version of the codex. 
In addition to consuming digital information, young people are creating it. Facebook, Napster, Google, Yahoo, and YouTube were all invented by students. The online environment is really a highly distributed built environment. Palfrey believes this environment can be remade; we do not need to leave it to the commercial vendors to control. Despite the recent rejection of the Google Books Settlement, we are very close to the possibility of a very large number of scanned books being made available by a single corporate player. Palfrey thinks this is very dangerous, and that this corpus of information would be better placed in the hands of librarians rather than a single corporation with a complicated author registry. Libraries can use this opportunity to work for something better.

It is in this context of change that the Harvard Library Transition is taking place. At Harvard, the libraries are being asked to do more with no additional resources. A focus on interdisciplinary and global issues in the curriculum means that the libraries must obtain a more materials, for example. Fortunately, the slow pace of change at Harvard is allowing time to develop arguments about the future of libraries and their role in the university. Palfrey believes that planning should begin with an architectural design process. Librarians should think like architects in this hybrid - virtual and real - space environment. If information exists in the cloud, how should we design physical spaces and interfaces? To begin we should ask users more about their experience through surveys and focus groups. We should have a sense of what others are doing and remain aware of best practices. We need to think differently in relation to our collections. What do we have a responsibility to keep, and when is providing access alone acceptable? Which parts of the collection should be considered temporary, and which permanent? We need to collaborate and work to reform the copyright law pertaining to orphan works. 
As part of this planning process, we need to increase our efforts to curate the content created by our own communities and build open-access information ecosystems. We need to think about how researchers will get to this information. It is not going into one big repository, but many local repositories. It is not enough to just put the information on the Web; we need to design discovery tools for accessing it. This will be the role of technical services in the future, in between the raw work of digitizing information and users searching for it, in creating discovery tools to make the information easy to find.

We cannot turn back the clock on researchers' use of Google and Google Scholar, but we should not allow ourselves to rely on Google. As librarians, we need to think about our entrance into this market. We need to be in the business of competing with Google. Doing so will require fruitful collaborations between technologists and librarians, with users as our informants. One example of this kind of collaboration is StackView from the Harvard Library Innovation Laboratory at Harvard Law School.

(http://librarylab.law.harvard.edu/projects/stackview/index.php). StackView is an online, visual representation of a shelf of books arranged by call number. The relative height of each book is derived from the book's dimensions as recorded in the catalog record, and the relative width is derived from the number of pages. The color of the book changes based on how many times it has circulated, providing an indication of usefulness. StackView could serve as a virtual, infinite shelf for browsing the content of all of Harvard's libraries online, an improvement over Harvard's physical libraries, which are geographically dispersed. By providing playful and 
interactive interfaces to represent the information created by technical services librarians that is stored in our catalogs and library systems, we can draw more people into our collections.

Palfrey concluded with the idea that librarians are more important than ever in the digital era, as researchers face information overload and concerns about the credibility of information. This presents a huge opportunity for librarians in helping people find their way through this new information environment. This is primarily a question of design; librarians can design pathways through an increasingly complicated, participatory information system, focusing on the user experience, in a way that creates joy and wonder. This will require invention and innovation. In order to make an argument for the future of libraries and for technical services, we need to get our hands dirty building the libraries of the future.

\section{Contact info:}

\section{Andrée J. Rathemacher}

Head, Acquisitions

University Libraries, University of Rhode Island

15 Lippitt Road

Kingston, RI 02881-2011

Phone: (401) 874-5096

Fax: (401) 874-4588

E-mail: andree@uri.edu

http://www.uri.edu/library/

\section{Michael A. Cerbo II}

Bibliographic Access \& Resource Management Librarian University Libraries, University of Rhode Island 15 Lippitt Road Kingston, RI 02881-2011 Phone: (401) 874-5967 
Fax: (401) 874-4588

E-mail: mcerbo@uri.edu

\section{Yuan Li}

Scholarly Communication Librarian

Syracuse University Library

Syracuse University

Syracuse, NY 13244-5040

E-mail: yli115@ @yr.edu 